\title{
Deciding to Wait: Partnership Status, Economic Conditions, and Pregnancy during the Great Recession
}

\author{
Christine Percheski, ${ }^{a}$ Rachel Tolbert Kimbro ${ }^{b}$
}

a) Northwestern University; b) Rice University

Abstract: The Great Recession was associated with reduced fertility in the United States. Many questions about the dynamics underlying this reduction remain unanswered, however, including whether reduced fertility rates were driven by decreases in intended or unplanned pregnancies. Using restricted data from the 2006-2010 National Survey of Family Growth $(N=4,630)$, we exploit variation in state economic indicators to assess the impact of economic conditions on the likelihood of an intended pregnancy, an unplanned pregnancy, or no pregnancy for adult women without a college education. We focus on variations by partnership and marital status. Overall, we find that worse economic conditions were predictive of a lower risk of unplanned pregnancy. Women's odds of intended pregnancy did not, however, respond uniformly to economic conditions but varied by marital status. When economic conditions were poor, married women had lower odds of intended pregnancy, whereas cohabiting women had greater odds of intended pregnancy.

Keywords: pregnancy; fertility; unemployment; recession; cohabitation

Citation: Percheski, Christine, and Rachel Tolbert Kimbro. 2017. "Deciding to Wait: Partnership Status, Economic Conditions, and Pregnancy during the Great Recession." Sociological Science 4: 176-195.

Received: September 23, 2016

Accepted: January 9, 2017

Published: February 20, 2017

Editor(s): Jesper Sørensen, Sarah Soule

DOI: $10.15195 / \mathrm{v} 4 . \mathrm{a} 8$

Copyright: (C) 2017 The Author(s). This open-access article has been published under a Creative Commons Attribution License, which allows unrestricted use, distribution and reproduction, in any form, as long as the original author and source have been credited. (1) (1)
THE "Great Recession" - the recent recession that officially began in December 2007 and ended in June 2009-had unequal economic and demographic consequences across the United States. Across the country, unemployment and mortgage foreclosure rates increased while consumer confidence levels dipped, but the extent of these changes varied considerably; some states registered small or no changes in economic indicators while others were heavily impacted. Demographic outcomes also changed unevenly during the Great Recession, with substantial variation in state-level fertility reductions (Cherlin et al. 2013; Morgan Cumberworth, and Wimer 2011).

Both theory and evidence from previous domestic and international recessions find that poor economic conditions are associated with lower fertility (Sobotka, Skirbekk, and Philipov 2011). Although new research by Schneider (2015) confirms the association between state-level economic conditions and general fertility rates (GFRs) in the United States during the Great Recession, many key questions about how the recession affected fertility remain unanswered.

In the United States, pregnancy and other family-related behaviors vary by both marital status and partnership status, but previous research has not investigated whether the Great Recession's impact on fertility differed by women's relationship status. Given that different norms and logics govern reproductive behavior for married, unmarried cohabiting, and unpartnered women (e.g., Hayford 2013; Musick 2002; Sweeney 2010), we hypothesize that women's pregnancy response to recessionary conditions may also differ by their relationship status. Addition- 
ally, most prominent explanations for fertility reductions during recessions assume rational actors with reproductive agency, suggesting that reductions in births during recessions are driven by reductions in planned or intended pregnancies. Yet, existing research has not examined whether decreases in intended or unintended pregnancies (or both) undergird the decline in births in the United States during the Great Recession. Nor has previous research identified whether changes in births owe to reduced sexual activity, increased contraceptive use, or increased abortions.

In this article, we investigate how intended and unplanned pregnancies changed during the Great Recession for adult women (ages 20-44) without a college degree, a group that experienced large changes in unemployment and mortgage delinquency rates during the Great Recession (Hoynes, Miller, and Schaller 2012; Wolff, Owens, and Burak 2011). We use the restricted version of the National Survey of Family Growth (NSFG) data (2006-2010) matched to state-level economic data to address the following questions: Between 2006 and 2010, what were the associations between economic conditions-specifically, unemployment rates, mortgage foreclosure rates, and consumer confidence levels-and the likelihood that an adult woman has an intended pregnancy, unintended pregnancy, or no pregnancy? Did married, cohabiting, and unpartnered women have similar responses to recessionary economic conditions? And do behavioral changes in sexual activity and contraceptive use covary with economic conditions? Answering these questions illuminates the dynamics behind fertility decline during the Great Recession and provides new insights into family life in the United States. Specifically, our analyses contribute to scholarly understandings of (1) how economic conditions affect reproductive behavior, (2) cohabitation as a family form, and (3) the dynamics of unplanned pregnancies.

\section{Conceptual Framework and Previous Research}

\section{Why Economic Conditions May Affect Reproductive Behavior}

Previous research holds that adverse economic conditions may lower fertility via two general mechanisms: income constraints and generalized uncertainty. In poor economic conditions, individuals may have fewer financial resources because of unemployment, wage stagnation, or losses in assets, and many individuals may defer having a first or an additional child in a period when their own resources and those of their social network are lower than usual. Poor economic conditions may also lead to a generalized sense of uncertainty about the future. Such uncertainty about one's own future and that of key social network members (who might provide social and economic support) may make long-term planning more difficult and decrease the likelihood of making the long-term commitment involved in having a child.

Alternatively, poor economic conditions may increase fertility or hasten childbearing for some population groups by lowering opportunity costs and increasing the salience of the parenting role. During periods of high unemployment, low wages, and slow wage growth, the opportunity costs of having a child (in terms of foregone wages and slower salary growth) are lower than they would be in times 
of economic prosperity (Morgan et al. 2011; Sobotka et al. 2011). Additionally, poor economic conditions may establish parenthood as a more important domain for accomplishment for both men and women (Morgan et al. 2011), as unemployment or stymied career prospects reduce their opportunities for finding personal fulfilment or gaining social status through employment.

These four mechanisms-income constraints, generalized uncertainty, lower opportunity costs, and increased salience of the parenting role-all assume rational and purposeful decision making by women or couples. If, however, stressful conditions affect decision making, then stress-impeded decision making may be another mechanism by which recessionary conditions affect fertility.

Previous research suggests that stress is linked to riskier sexual activity (Mazzaferro et al. 2006) and that financial hardship and poverty impede cognitive function (Mani et al. 2013). During a recession, stress from job loss, mortgage foreclosure, or other financial hardships may impair an individual's ability to make sound decisions. Because approximately 85 percent of sexually-active women of reproductive age will become pregnant within a year if they take no measures to avoid pregnancy (Trussell 2011), sexually-active women must actively decide to prevent pregnancy and consistently use contraception in order to avoid it. If stress and financial hardships impede rational decision making and purposeful behavior, we might expect increased odds of unplanned pregnancies among women who were most negatively impacted by the recession.

\section{Previous Research on the Great Recession and Fertility}

Because of the recentness of the Great Recession and data availability constraints, much of the published research on fertility change in the United States during the Great Recession has been based on aggregate data on births. Using data at the national level, Sutton, Hamilton, and Mathews (2011) find declines in births of four percent among the population of women aged 15-44, with substantial variations by age, race/ethnicity, and number of previous births (parity). Additionally, Morgan et al. (2011) and Cherlin et al. (2013) find strong correlations between state unemployment rates and state birth rates.

Two recent articles by Schneider examine the Great Recession's effects on fertility in more detail. In one study, Schneider (2015) finds that state-level GFRs were lower when unemployment rates and foreclosure start rates were higher. In a second study, Schneider and Hastings (2015) find that poor state-level economic conditions reduce the likelihood that unmarried low-SES women enter into marriage or have a nonmarital birth.

Collectively, previous studies paint a broad picture of the contours of fertility decline during the Great Recession, but there are still notable gaps in our understanding of how the Great Recession affected fertility. First, previous studies have grouped all unmarried women together, regardless of partnership status, even though women with cohabiting partners are unlike unpartnered women in many aspects of reproductive behavior and family life, and approximately one-quarter of births in the United States are to cohabiting women (Monte and Ellis 2014). Though cohabitation has become widely accepted as a living arrangement for childless 
couples, marriage remains a more common context for first pregnancy in the United States (see review in Sweeney and Raley 2014), and fertility among married women is largely planned (Mosher, Jones, and Abma 2012). Although Sweeney (2010) finds that never-married, cohabiting women and married women with low levels of educational attainment have similar birth control practices, rates of unintended pregnancies are still two to three times higher for cohabiting women than for married women (Finer and Zolna 2011). Cohabiting women are also dissimilar from unpartnered women in their reproductive behavior. For example, only one-third of births to unpartnered women are described as intended compared to approximately half of births to cohabiting women (Mosher et al. 2012).

Second, most studies of births do not give us information on the intentionality of pregnancies that result in live births or any information about pregnancies that do not result in live births, although there is some evidence that unintended pregnancy rates declined between 2008 and 2011 (Finer and Zolna 2016). Live births that result from unintended pregnancies are strongly associated with reduced couple stability (Guzzo and Hayford 2012), poorer parental psychological well-being (Su 2012), and differences in maternal parenting behaviors and child wellbeing (e.g., Barber, Axinn, and Thornton 1999; Saleem and Surkan 2014 but see Joyce, Kaestner, and Korenman 2000). Third, no studies to date have examined how the proximate determinants of fertility (Bongaarts 1978; Davis and Blake 1956), such as contraceptive use, changed during the recession; we answer Schneider (2015)'s call for such an analysis.

\section{Our Analysis}

We use restricted data from the 2006-2010 NSFG matched to indicators of state-level economic conditions to examine how the recession impacted the likelihood of an intended pregnancy, an unplanned pregnancy, or no pregnancy. We test for differences by relationship status (married, cohabiting, and unpartnered) in the pregnancy responsiveness to economic conditions. Unlike most previous studies of recession and fertility (except Schneider 2015; Schneider and Hastings 2015), we do not limit our definition of economic conditions to employment-related measures; rather, we include additional measures of mortgage foreclosure inventories and consumer confidence levels in our investigation. Employment conditions are not perfectly correlated with housing dynamics or consumer confidence, and individuals are likely taking cues about economic conditions from multiple dimensions of their environment. Additionally, we investigate changes in two proximate determinants of pregnancy: sexual activity and contraceptive use.

We restrict our analysis to women without a college degree for two reasons. First, individuals without a college degree were more impacted by the recession than college-educated individuals, as evidenced by higher unemployment rates (Hoynes et al. 2012) and higher mortgage delinquency rates (Wolff et al. 2011). Second, women's fertility patterns and experiences, including rates of unintended pregnancies, differ sharply based on whether they have obtained a college degree (e.g., Mosher et al. 2012; Musick 2002).

Our focus on pregnancies (versus live births) allows us to examine pregnancy intendedness and the proximate determinants of pregnancy, which are not possible 
to do using birth data from sources used in previous research, such as Vital Statistics (e.g., Cherlin et al. 2013; Morgan et al. 2011; Schneider 2015; Sutton et al. 2011) or the American Community Survey (Schneider and Hastings 2015). Differences between pregnancy rates and birth rates are attributable to factors affecting successful gestation and partition, which (in the United States) are primarily elective abortions and spontaneous abortions (i.e., miscarriages). Nationally representative, individual-level data on abortions in the United States tremendously underestimate the prevalence of abortion (Jones and Kost 2007; U.S. Department of Health and Human Services 2011), making it difficult to examine whether the responsiveness of abortion rates to economic conditions differs by partnership status. Notably, estimates of abortion rates based on provider data for 2008 and 2009 show a decrease in abortion compared to the early 2000s (Pazol et al. 2012). Additionally, Finer and Zolna (2016) find that the percentage of (self-reported) unintended pregnancies that ended in abortion was similar in 2008 and 2011. These findings suggest that fertility declines during the Great Recession were not due to increases in abortion. Relatively little is known about the factors affecting miscarriage risk (see discussion in Lang and Nuevo-Chiquero 2012), but there is no evidence that poor economic conditions cause increases in miscarriage ${ }^{1}$. In summary, our estimates of the associations between state-level economic conditions and pregnancy are not equivalent to estimates of the associations of state-level economic conditions with births, but they are likely to be quite similar.

\section{Data}

We use individual-level data from the 2006-2010 National Survey of Family Growth (Respondent and Pregnancy files) merged with data on state-level economic conditions. Because the geographic variables in the NSFG data are restricted, merging data on state-level economic conditions with individual-level data required approval from the National Center for Health Statistics (NCHS) and our use of the resulting merged data at a census or NCHS Restricted Data Center (RDC).

The NSFG surveys are cross-sectional, nationally representative household surveys of U.S. women aged 15-44 that gather retrospective data related to fertility, family formation, and contraception. Detailed partnership and fertility histories are collected, enabling us to identify women who became pregnant or had a birth during a specified window. (Information on sexual activity and whether the woman used contraceptives in the previous year is also available.) Our analytic sample includes women between the ages of 20 and 44 who neither had a college degree nor were pregnant or surgically sterilized as of 12 months before the survey interview date. This is the pool of women that we define as "at risk" of becoming pregnant during the year preceding the survey-the observation period.

In the NSFG 2006-2010 data, 7,038 respondents were ages 20 and older and did not have a college degree. Of these, we exclude respondents not at risk of pregnancy: 1,956 respondents who had had surgical sterilization procedures and 397 respondents who were pregnant at the start of the observation window (exactly one year before the survey date). We also exclude three respondents who had been married four or more times who are missing data on marital status at the start of 
the observation window, and 62 respondents who are missing data on other key variables. Our final analytic sample includes 4,630 respondents who are at risk of pregnancy and had complete data on outcome and control variables.

\section{Outcome Variables}

Our main outcome variable is a categorical variable indicating whether the NSFG respondent had no pregnancy (reference category), an intended pregnancy, or an unplanned pregnancy during the observation window. We created this variable using the respondent's pregnancy history (from the pregnancy files), which includes exact pregnancy start dates for all current and previous pregnancies (not just those resulting in a live birth). For each pregnancy, respondents indicated whether the timing of the pregnancy was "later or overdue," "right time," "too soon, mistimed," "unwanted," or "indifferent" or "don't know." We coded pregnancies that the respondents identified as "later or overdue" and "right time" as intended and all other pregnancies, including "indifferent" or "don't know," as unplanned.

We also examine sexual activity status and contraceptive use. Sexual activity status is a dichotomous indicator of whether a woman reported vaginal sexual intercourse with a male partner during the observation period. Contraceptive use is a dichotomous indicator of whether a sexually active woman reported using contraceptives at any point in the observation period.

We limit our observation period to the year before the survey because (1) reports on pregnancy timing, sexual activity, and contraceptive use may be less accurate for longer periods of recall, and (2) economic conditions are matched to where the respondent lived at the time of the survey interview, and the longer the observation window, the greater the risk that the respondent may have moved to a different state.

\section{Population Subgroup Definitions}

We classified our sample into three categories (married, cohabiting, unpartnered) based on their relationship status at of the start of the observation period as determined by their marital and cohabitation histories. The category of cohabiting women includes never married and previously married women. Likewise, the unpartnered category includes all women who were neither married nor cohabiting at the start of the observation window, regardless of marital history. Of our analytic sample, 1,440 were married women, 884 were cohabiting and unmarried women, and 2,306 were "unpartnered" women-meaning that they were not in a coresidential sexual union at the start of our observation window.

\section{Individual Characteristics}

We include a limited set of covariates that are known to affect intended and unplanned pregnancy rates and that are most likely to moderate or interact with economic conditions. Variables for all women include the following: age (with the following categorical variables ${ }^{2}$ : 20-24, 25-29, 30-34, 35-44), race/ethnicity 
(non-Hispanic white, non-Hispanic black, Hispanic, other and/or multiple races), nativity status (indicator variable for immigrant), educational attainment (less than high school, high school, or some college), and the number of children that the woman has $(0,1,2$, or more). For partnered women, we also include variables for whether she has children from a previous partner and whether her partner has children from a previous partner; we include these variables because theory suggests that multipartner fertility may differ in important ways from single-partner fertility (Carlson and Furstenberg 2006; Guzzo 2014). Appendix Table 1 (online supplement) shows descriptive statistics of our sample by relationship status.

\section{Geographic Variables}

We include two variables related to the geographic location of our sample of NSFG respondents: region (Northeast, Midwest, South, and West), which is available through the restricted data file only, and an indicator of whether the respondent does not live in a metropolitan area (rural area), available from the public version of the NSFG data files.

\section{Economic Conditions}

We operationalize economic conditions by annual ${ }^{3}$ measures of state-level unemployment, mortgage foreclosures, and consumer confidence levels merged onto the restricted version of the NSFG data. We use the value of the variable from the year in which the observation period started. For example, a woman who was interviewed in February 2010 would have an observation period of February 2009-February 2010, and we would use economic values from 2009.

We investigated multiple specifications and transformations of each economic variable, including linear and squared terms, the logged form, and categorical variables denoting values in the top and bottom quartile. We chose the best fitting specification for each measure, and the specifications that we include in our final models are as follows:

1. State unemployment rate for the total population (logged) from the Bureau of Labor Statistics (BLS).

2. State mortgage foreclosure inventory (linear) from the Mortgage Bankers Association's National Delinquency Survey.

3. State-level ${ }^{4}$ consumer confidence ratings (linear but scaled by a factor of 10 to ease interpretation) from the Survey of Consumers using a custom tabulation provided by University of Michigan's Survey of Consumers research staff.

In Appendix Table 2 (online supplement), we present descriptive statistics for our measures of economic conditions. ${ }^{5}$ There is considerable variation in all of our economic measures. Among the 50 states and the District of Columbia across the years of our study, the correlations between variables are as follows: unemployment and consumer confidence -0.53 , consumer confidence and mortgage foreclosure -0.42 , and unemployment rate and mortgage foreclosure rate 0.69 . Thus, 
the three state measures have moderately high correlation but do not covary perfectly, suggesting that they capture qualitatively different dimensions of economic conditions.

The unemployment rate is also available at the Core Based Statistical Area (CBSA) level; we investigate the associations between CBSA unemployment rates ${ }^{6}$ and pregnancy as a robustness check. (We find the same pattern of results using CBSA and state unemployment, including nearly identical point estimates in many models.)

Given our sample size and the number of respondents per state, including state fixed effects is not possible. ${ }^{7}$ Instead, to account for long-standing differences in economic conditions across geographic areas, we include variables for the median county per capita income between 2005-2009 and county unemployment (logged) in the year 2000 (both available from the restricted NSFG files).

\section{Analytic Strategy}

The 2006-2010 NSFG data are nationally representative when the survey weights are used. We account for the complex sampling design by utilizing the stratum and cluster variables provided by the NSFG along with the weight WGTQ1Q16 with the SVY series of commands in Stata.

We estimate the prevalence of any pregnancy, intended or planned pregnancy, and unplanned pregnancy for each population subgroup and examine within-group variations in pregnancy prevalence by age, race/ethnicity, education, and parity.

We turn to a regression framework to estimate the associations of economic conditions with pregnancy, net of key demographic characteristics. We model the probability of three pregnancy-related outcomes: no pregnancy (reference group), intended pregnancy, and unplanned pregnancy using multinomial logit models. We start by modeling pregnancy for the whole population, pooling married, cohabiting, and unpartnered women. In our next set of models, we model pregnancy separately for each subgroup (married, cohabiting, and unpartnered). We then test for interactions between economic conditions and relationship status, testing for differences by marital status among all women and for differences by partnership status among unmarried women. ${ }^{8}$ Additionally, we examine how economic conditions associate with intended pregnancies among partnered women with no previous births. In a final set of analyses, we model the association between economic conditions and sexual activity for unpartnered women and contraceptive use for all sexually active women. Please note that full results from our regression models are available in the online supplement.

\section{Findings}

\section{Pregnancy Rates by Population Subgroups}

In Table 1, we show the percentage of women with no pregnancy, an intended pregnancy, and unplanned pregnancy in the one-year observation window by partnership status. Notably, married and cohabiting women show similar overall 


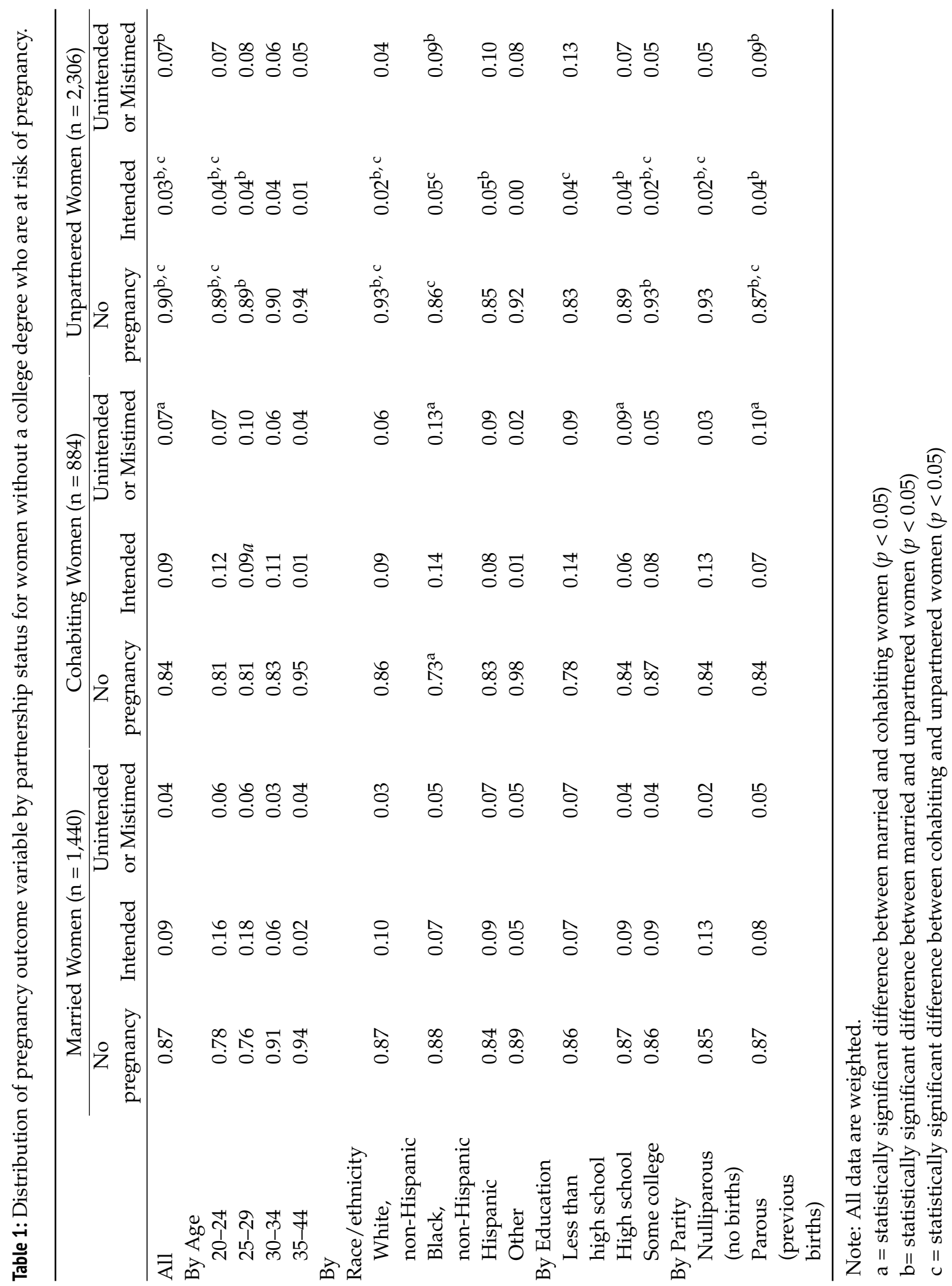


pregnancy rates ( 0.13 for married women and 0.16 for cohabiting women), whereas unpartnered women have a pregnancy rate substantially lower than that for partnered women (0.10); the differences between partnered women and unpartnered women are statistically significant $(p<0.05)$. Table 1 shows that a high percentage of married women's pregnancies are intended (69 percent; 0.09 of 0.13 ) in contrast with a low percentage of unpartnered women's pregnancies (30 percent; 0.03 of 0.10). Cohabiting women's share of pregnancies that are intended (56 percent; 0.09 of 0.16 ) is more similar to that of married women than to unpartnered women.

When we look within demographic groups defined by age, race, education, or parity, we find only one statistically significant difference in the percentages of women with intended pregnancy between married and cohabiting women, but there are several statistically significant differences between married and cohabiting women in unplanned pregnancy rates. For many population subgroups, unpartnered women have substantially (and statistically significant) differences in intended pregnancy rates than married and cohabiting women; interestingly, there are no statistically significant differences in unplanned pregnancy rates between unpartnered and cohabiting women. Taken together, these differences in pregnancy rates suggest that the conventional classification of women by marital status and pooling all pregnancies together (regardless of their intendedness) may be blurring important differences in pregnancy risk.

\section{Associations between Economic Conditions and Pregnancy}

The regression analyses (Table 2) show how measures of economic conditions are associated with the log odds of intended pregnancy and unplanned pregnancy (relative to the reference category of no pregnancy) among all women. From the three models, each with a different measure of economic conditions, a consistent pattern emerges: recessionary economic conditions (as indicated by higher unemployment rates, higher foreclosure rates, and lower consumer confidence levels) are associated with a lower probability of unplanned pregnancy, net of other characteristics. Additionally, higher mortgage foreclosure rates and lower consumer confidence levels are associated with a lower probability of intended pregnancy. For intended pregnancy, the coefficient on the unemployment variable, though not statistically significant at conventional levels, is signed in the direction consistent with the pattern of worse economic conditions predicting lower odds of intended pregnancy. These analyses suggest that lower birth rates during the Great Recession resulted from changes in both intended and unplanned pregnancy rates. Additionally, the results show that the probability of having an intended pregnancy, relative to no pregnancy, is considerably lower for unpartnered women than for married women, controlling for other characteristics. Cohabiting women also have a lower probability of having an intended pregnancy than married women, though this difference just misses conventional cutoffs for statistical significance.

Turning to differences by population subgroups defined by marital and partnership status, a more nuanced picture emerges. Among married women (panel A of Table 3), we see that unemployment rates and consumer confidence levels show a statistically significant association $(p<0.05)$ with intended pregnancy. Holding 
Table 2: Coefficients from mlogit models predicting intended and unintended pregnancy relative to no pregnancy by state-level economic conditions with covariates for partnership status. (Sample: all fertile adult women without a college degree. $n=4,630$.)

\begin{tabular}{lccc}
\hline & $\begin{array}{c}\text { Model 1 } \\
\text { Unemployment }\end{array}$ & $\begin{array}{c}\text { Model 2 } \\
\text { Consumer Confidence }\end{array}$ & $\begin{array}{c}\text { Model 3 } \\
\text { Mortgage Foreclosure }\end{array}$ \\
\hline Intended Pregnancy & & & \\
Main effect of economic variable & -0.31 & $0.11^{*}$ & $-0.12^{\dagger}$ \\
& $(0.27)$ & $(0.07)$ & $(0.05)$ \\
Cohabiting & $-0.45^{*}$ & $-0.41^{*}$ & $-0.43^{*}$ \\
& $(0.23)$ & $(0.23)$ & $(0.23)$ \\
Unpartnered & $-1.54^{\dagger}$ & $-1.48^{\dagger}$ & $-1.53^{\dagger}$ \\
& $(0.27)$ & $(0.26)$ & $(0.27)$ \\
Constant & -3.62 & -5.11 & -3.72 \\
& $(0.92)$ & $(1.05)$ & $(0.87)$ \\
Unintended Pregnancy & & & \\
Main effect of economic variable & $-0.52^{\dagger}$ & $0.13^{*}$ & $-0.16^{\dagger}$ \\
& $(0.26)$ & $(0.07)$ & $(0.06)$ \\
Cohabiting & 0.29 & 0.38 & 0.31 \\
& $(0.27)$ & $(0.27)$ & $(0.27)$ \\
Unpartnered & 0.41 & $0.49^{*}$ & 0.42 \\
Constant & $(0.25)$ & $(0.26)$ & $(0.25)$ \\
& -4.43 & -6.50 & -4.79 \\
& $(1.05)$ & $(1.42)$ & $(1.08)$ \\
\hline
\end{tabular}

$+p<0.05 ; * p<0.10$.

Models include all of the demographic characteristics from Appendix Table 1, geographic region, county unemployment in the year 2000, and county per capita income averaged across 2005-2009.

other characteristics constant, the probability of an intended pregnancy is lower for women when unemployment rates are high, and the probability of intended pregnancy is higher when consumer confidence is stronger. Our findings are consistent with the general theoretical expectation that poor economic conditions are associated with lower intended pregnancy rates. Additionally, although none of the economic predictors are predictive of unintended pregnancy for married women at conventional cutoffs for statistical significance, the coefficients on the unemployment variables are large and suggest that higher rates of unemployment are associated with a lower probability of unintended pregnancy.

Table 3, panel B shows models of pregnancy among cohabiting women. Our models do not show any associations between economic indicators and pregnancy that are statistically significant at conventional levels $(p<0.05)$, though the coefficient on the unemployment rate was large and positive for intended pregnancy; this suggests that cohabiting women may be responding to the lower opportunity costs of childbearing during recessions.

For unpartnered women, there is a strong, negative association between mortgage foreclosure rates and unplanned pregnancy (see Table 3, panel C). Unpartnered 
Table 3: Coefficients from mlogit models predicting intended and unintended pregnancy relative to no pregnancy by state-level economic conditions with covariates for partnership status. (Sample: all fertile adult women without a college degree. $n=4,630$.)

\begin{tabular}{|c|c|c|c|}
\hline & $\begin{array}{c}\text { Model } 1 \\
\text { Unemployment }\end{array}$ & $\begin{array}{c}\text { Model } 2 \\
\text { Consumer } \\
\text { Confidence }\end{array}$ & $\begin{array}{c}\text { Model } 3 \\
\text { Mortgage } \\
\text { Foreclosure }\end{array}$ \\
\hline \multicolumn{4}{|l|}{ Panel A: Married Women $(n=1,440)$} \\
\hline Main effect of economic variable & $\begin{array}{r}-0.91^{\dagger} \\
(0.36)\end{array}$ & $\begin{array}{c}0.19^{\dagger} \\
(0.09)\end{array}$ & $\begin{array}{c}-0.09 \\
(0.07)\end{array}$ \\
\hline \multicolumn{4}{|l|}{ Unintended Pregnancy } \\
\hline Main effect of economic variable & $\begin{array}{c}-0.61 \\
(0.44)\end{array}$ & $\begin{array}{c}0.16 \\
(0.14)\end{array}$ & $\begin{array}{c}-0.08 \\
(0.10)\end{array}$ \\
\hline \multicolumn{4}{|l|}{ Panel B: Cohabiting Women $(n=884)$} \\
\hline Main effect of economic variable & $\begin{array}{c}0.87^{*} \\
(0.47)\end{array}$ & $\begin{array}{c}-0.07 \\
(0.16)\end{array}$ & $\begin{array}{c}-0.09 \\
(0.10)\end{array}$ \\
\hline \multicolumn{4}{|l|}{ Unintended Pregnancy } \\
\hline Main effect of economic variable & $\begin{array}{c}-0.17 \\
(0.57)\end{array}$ & $\begin{array}{c}0.15 \\
(0.13)\end{array}$ & $\begin{array}{c}-0.08 \\
(0.10)\end{array}$ \\
\hline \multicolumn{4}{|c|}{ Panel C: Unpartnered Women $(n=2,306)$} \\
\hline Main effect of economic variable & $\begin{array}{c}-0.26 \\
(0.57)\end{array}$ & $\begin{array}{c}0.17 \\
(0.14)\end{array}$ & $\begin{array}{c}-0.22 \\
(0.15)\end{array}$ \\
\hline \multicolumn{4}{|l|}{ Unintended Pregnancy } \\
\hline Main effect of economic variable & $\begin{array}{c}-0.53 \\
(0.45)\end{array}$ & $\begin{array}{c}0.11 \\
(0.12)\end{array}$ & $\begin{array}{r}-0.26^{\dagger} \\
(0.10)\end{array}$ \\
\hline
\end{tabular}

$+p<0.05 ; * p<0.10$.

Models include all of the demographic characteristics from Appendix Table 1, geographic region, county unemployment in the year 2000, and county per capita income averaged across 2005-2009.

women are less likely to have an unwanted or mistimed pregnancy relative to no pregnancy when state mortgage foreclosure rates are high $(B=-0.26, p$ value $<$ 0.05 .), all other factors equal. The coefficient on the unemployment variable is large and negative, suggesting that unintended pregnancy is also less common when unemployment rates are high.

Results from these models run separately by relationship status suggest that there may be differences in the associations of economic conditions with pregnancy by relationship status. To formally test whether these associations differ, we fit several additional models. The models in Table 4, panel A include interactions between marital status and economic condition variables. We find statistically significant interactions between the unemployment variable and the married variable for intended pregnancy, indicating that employment conditions associated differently with intended pregnancy for married women than for unmarried women. 
More specifically, higher unemployment is associated with a lower relative risk of intended pregnancy for married women. We do not find any other statistically significant interactions between marital status and economic variables.

In Table 4, panel B, we show results from models examining differences among unmarried women. These models show just one statistically significant difference in the odds of intended and unplanned pregnancy by cohabiting status; in the model with mortgage foreclosure rates, cohabiting women have greater odds of having an intended pregnancy versus no pregnancy, net of other characteristics, than unpartnered women. Moreover, there are no statistically significant differences between cohabiting and unpartnered women in the associations of economic conditions with either intended or unplanned pregnancy. Many of the estimates from these models have large standard errors; thus, we cannot rule out the possibility of small differences between cohabiting and unpartnered women.

Taken together, the models in Table 4 show that married women are distinct from unmarried women in their responsiveness to recessionary conditions, and that cohabiting women are not statistically different from unpartnered women. In additional models (available upon request), we test whether there are statistically significant differences between married and cohabiting women in responsiveness to recessionary conditions. We find statistically significant interactions between unemployment rates and cohabiting status, suggesting that cohabiting women's odds of intended pregnancy are greater with higher unemployment rates, whereas those of married women are lower.

The decision to have a first child may associate differently with economic conditions than the decision to have an additional child. The direct costs of providing for a first child are likely higher than for subsequent children because many of the material costs associated with infants (e.g., purchasing a crib, infant car seat, stroller, etc.) are incurred only with the first birth, though the costs of diapers and nutrition are likely to be similar across parities. Perhaps more important than the direct costs are the opportunity costs for mothers in terms of foregone employment and wages. Budig and England (2001) find that the wage penalties associated with motherhood are not linearly related to the number of children: "Second children reduce wages more than a first child" (p. 220). This suggests that the opportunity cost of higher parity births may be greater than that of first births.

To examine how economic conditions associate with the decision to have a first child, we concentrate our next analysis on intended pregnancies among childless married and cohabiting women, excluding unpartnered women. Using logit models to examine the associations between economic conditions and intended pregnancy for married women and cohabiting women (in separate models) without a previous birth, we find that all three economic variables have statistically significant associations with intended births for married women: worse economic conditions are associated with lower odds of an intended pregnancy (see Table 5). In contrast, for cohabiting women, higher unemployment rates are associated with greater odds of intended pregnancy. Further analyses by parity (results available upon request) for married women show no associations between economic conditions and intended or unplanned pregnancy for women with one child but statistically significant negative associations between unemployment rates and pregnancy among married 
Table 4: Coefficients from mlogit models predicting intended and unintended pregnancy relative to no pregnancy by state-level economic conditions with interactions for partnership or marital status.

\begin{tabular}{|c|c|c|c|}
\hline & $\begin{array}{c}\text { Model } 1 \\
\text { Unemployment }\end{array}$ & $\begin{array}{c}\text { Model } 2 \\
\text { Consumer } \\
\text { Confidence }\end{array}$ & $\begin{array}{c}\text { Model } 3 \\
\text { Mortgage } \\
\text { Foreclosure }\end{array}$ \\
\hline \multicolumn{4}{|l|}{ Panel A: All Women $(n=4,630)$} \\
\hline Main effect of economic variable & $\begin{array}{c}0.52 \\
(0.33)\end{array}$ & $\begin{array}{c}0.03 \\
(0.11)\end{array}$ & $\begin{array}{c}-0.08 \\
(0.08)\end{array}$ \\
\hline Married & $\begin{array}{r}3.11^{\dagger} \\
(0.90)\end{array}$ & $\begin{array}{c}-0.98 \\
(1.21)\end{array}$ & $\begin{array}{c}0.55 \\
(0.33)\end{array}$ \\
\hline Unpartnered & $\begin{array}{r}-1.11^{+} \\
(0.32)\end{array}$ & $\begin{array}{r}-1.07 \\
(0.32)\end{array}$ & $\begin{array}{r}-1.09^{+} \\
(0.32)\end{array}$ \\
\hline Interaction with married & $\begin{array}{r}-1.60^{\dagger} \\
(0.54)\end{array}$ & $\begin{array}{c}0.17 \\
(0.14)\end{array}$ & $\begin{array}{c}-0.06 \\
(0.13)\end{array}$ \\
\hline \multicolumn{4}{|l|}{ Unintended Pregnancy } \\
\hline Main effect of economic variable & $\begin{array}{c}-0.44 \\
(0.33)\end{array}$ & $\begin{array}{c}0.13 \\
(0.09)\end{array}$ & $\begin{array}{r}-0.20^{+} \\
(0.07)\end{array}$ \\
\hline Married & $\begin{array}{c}0.09 \\
(1.00)\end{array}$ & $\begin{array}{l}-0.36 \\
(1.46)\end{array}$ & $\begin{array}{c}-0.56 \\
(0.41)\end{array}$ \\
\hline Unpartnered & $\begin{array}{c}0.12 \\
(0.22)\end{array}$ & $\begin{array}{c}0.12 \\
(0.23)\end{array}$ & $\begin{array}{c}0.10 \\
(0.22)\end{array}$ \\
\hline Interaction with married & $\begin{array}{c}-0.23 \\
(0.58)\end{array}$ & $\begin{array}{c}0.00 \\
(0.02)\end{array}$ & $\begin{array}{c}0.13 \\
(0.14)\end{array}$ \\
\hline \multicolumn{4}{|c|}{$\begin{array}{l}\text { Panel B: Unmarried Women (cohabiting \& unpartnered) } \\
\text { Intended Pregnancy }\end{array}$} \\
\hline Main effect of economic variable & $\begin{array}{c}0.16 \\
(0.54)\end{array}$ & $\begin{array}{c}0.12 \\
(0.14)\end{array}$ & $\begin{array}{c}-0.16 \\
(0.15)\end{array}$ \\
\hline Cohabiting & $\begin{array}{c}0.36 \\
(1.38)\end{array}$ & $\begin{array}{c}2.22 \\
(1.68)\end{array}$ & $\begin{array}{l}1.06^{*} \\
(0.50)\end{array}$ \\
\hline Interaction with cohabiting & $\begin{array}{c}0.42 \\
(0.78)\end{array}$ & $\begin{array}{c}-0.15 \\
(0.20)\end{array}$ & $\begin{array}{c}0.02 \\
(0.17)\end{array}$ \\
\hline \multicolumn{4}{|l|}{ Unintended Pregnancy } \\
\hline Main effect of economic variable & $\begin{array}{c}-0.47 \\
(0.41)\end{array}$ & $\begin{array}{c}0.11 \\
(0.12)\end{array}$ & $\begin{array}{r}-0.24^{*} \\
(0.10)\end{array}$ \\
\hline Cohabiting & $\begin{array}{c}-0.27 \\
(1.27)\end{array}$ & $\begin{array}{c}-0.65 \\
(1.41)\end{array}$ & $\begin{array}{c}-0.31 \\
(0.36)\end{array}$ \\
\hline Interaction with cohabiting & $\begin{array}{c}0.10 \\
(0.74)\end{array}$ & $\begin{array}{c}0.07 \\
(0.17)\end{array}$ & $\begin{array}{c}0.11 \\
(0.14)\end{array}$ \\
\hline
\end{tabular}

$+p<0.01 ; * p<0.05$.

Models include all of the demographic characteristics from Appendix Table 1, geographic region, county unemployment in the year 2000, and county per capita income averaged across 2005-2009. 
Table 5: Coefficients from logit models predicting intended pregnancy by local economic conditions for women without a previous birth.

\begin{tabular}{|c|c|c|c|}
\hline & $\begin{array}{c}\text { Model } 1 \\
\text { Unemployment }\end{array}$ & $\begin{array}{c}\text { Model } 2 \\
\text { Consumer } \\
\text { Confidence }\end{array}$ & $\begin{array}{c}\text { Model } 3 \\
\text { Mortgage } \\
\text { Foreclosure }\end{array}$ \\
\hline \multicolumn{4}{|l|}{ Panel A: Married Women $(n=273)$} \\
\hline Main effect of economic variable & $\begin{array}{r}-1.68^{\dagger} \\
(0.74)\end{array}$ & $\begin{array}{c}0.53^{\dagger} \\
(0.21)\end{array}$ & $\begin{array}{r}-0.54^{\dagger} \\
(0.25)\end{array}$ \\
\hline \multicolumn{4}{|l|}{ Panel B: Cohabiting Women $(n=210)$} \\
\hline Main effect of economic variable & $\begin{array}{r}2.46^{\dagger} \\
(0.89)\end{array}$ & $\begin{array}{r}-0.53^{*} \\
(0.29)\end{array}$ & $\begin{array}{c}0.03 \\
(0.18)\end{array}$ \\
\hline
\end{tabular}

$+p<0.05 ; * p<0.10$.

Models include all of the demographic characteristics from Appendix Table 1, geographic region, county unemployment in the year 2000, and county per capita income averaged across 2005-2009.

women with two children. For cohabiting women, there are no statistically significant associations between economic conditions and pregnancy for women with one child, though the estimates are noisy because of small sample sizes.

\section{Proximate Determinants of Pregnancy}

To investigate the mechanisms behind lower pregnancy during the Great Recession, we examined the associations between economic conditions and two proximate determinants of pregnancy: sexual activity and contraceptive use. Using a logistic regression framework and the same set of control variables as in our analyses of pregnancy, we model whether (during the observation period) the respondent (1) was sexually active ${ }^{9}$ (unpartnered women only ${ }^{10}$ ) and (2) used contraceptives (all sexually active women) ${ }^{11}$ (see Appendix Table 3 , online supplement.).

We find that none of the indicators of economic conditions were associated with the odds of being sexually active in the previous year at conventional levels of statistical significance. The coefficient on consumer confidence approaches the conventional cutoff for statistical significance $(B=-0.10, p<0.10)$ and indicates that greater levels of consumer confidence are associated with lower odds of sexual intercourse in the previous year among unpartnered women. Our model predicts that 79.6 percent of unpartnered women (with reference characteristics) would be sexually active when consumer confidence ratings were at their 2006 level for California compared with 84.6 percent of unpartnered women when consumer confidence ratings were at their 2008 value for California. Based on these analyses, we conclude that a decrease in the share of sexually active women is very unlikely to be the mechanism behind lower fertility during the Great Recession.

Our models of contraceptive use showed no statistically significant associations between state-level economic conditions and contraceptive use among married or cohabiting women. Interestingly, higher consumer confidence levels are associated 
with lower contraceptive use among unpartnered women, albeit at levels that just miss the conventional cutoffs for statistical significance $(p<0.10)$.

\section{Conclusions}

The Great Recession was associated with reduced period fertility in industrialized countries around the world, including the United States. Partially because of data availability constraints, much is still unknown about how fertility was affected by the recession. Using the restricted version of the National Survey of Family Growth data from 2006-2010 linked to state-level economic conditions, we examine pregnancy during a one-year observation period for adult women without a college education who are "at risk" of pregnancy.

Consistent with findings on the Great Recession's impact on births, we find that poor economic conditions are associated with a lower overall likelihood of pregnancy. Our analysis also uncovers important but previously overlooked differences in pregnancy rates by intendedness. For the total population of adult women without a college degree, we find that higher mortgage foreclosure inventories are associated with lower odds of both intended and unplanned pregnancies ( $p$ $<0.05)$. We also find that higher unemployment rates are associated with lower odds of unplanned pregnancy $(p<0.05)$ and that lower consumer confidence is associated with both lower odds of intended and unplanned pregnancy $(p<0.10)$. We find no evidence that stress-induced decision making operated to increase unplanned pregnancies during the recession. Instead, women seem to respond to the economic conditions with rational and purposeful reproductive behavior. Overall, women have both fewer intended and unplanned pregnancies under recessionary conditions.

Underlying these findings for the total population, however, are different responses by relationship status. Married women, especially those with no previous births, have lower odds of intended pregnancy when unemployment rates are high and consumer confidence levels are low. In contrast, odds of intended pregnancy are higher for cohabiting women with no previous births when unemployment is high.

Our analyses of two proximate determinants of pregnancy give some hints as to the mechanisms behind fertility decline. We find suggestive evidence that unpartnered women may be more likely to be sexually active when economic conditions are poor; thus, lower rates of sexual activity cannot be a mechanism behind fertility decline. We also find weak but suggestive evidence that contraceptive use is lower among unpartnered women when consumer confidence levels are high. We suspect that contraceptive consistency may have been higher in poor economic conditions, though we leave this as a question for future researchers.

Our analysis has several limitations. First, restrictions that accompany use of the restricted version of the NSFG preclude a thorough examination of trends in small population groups. Additionally, the relatively small sample size for cohabiting women impedes identification of associations that are small in magnitude between pregnancy and economic conditions for this group. Second, our economic measures are at the state level and thus may not reflect the conditions in respondents' 
communities, particularly in large states or for respondents in metropolitan areas that straddle state borders. Finally, the NSFG does not include questions about an individual's financial stress, mortgage foreclosure experiences, or unemployment histories, so we cannot determine whether effects are different for women most directly impacted by the Great Recession. More research is needed to understand whether women are responding to changed economic conditions for their own household, for their social network, or for the broader population in their state.

Despite these limitations, our analysis contributes several key findings to scholarly understanding of the Great Recession and of families. First, our results speak to the unique characteristics of cohabitation as a family form in the United States. We show that married and cohabiting women have similar rates of intended pregnancies, especially among nulliparous women. Cohabiting women, however, respond quite differently to recessionary conditions than married women, suggesting a different calculus of the costs, benefits, and conditions under which one should start or enlarge a family. Thus, our analyses provide further evidence that cohabitation has norms and dynamics that remain distinct from marriage.

Second, our finding that unplanned pregnancies are responsive to economic conditions has several implications. Our results suggest that U.S. women exercise more agency in reproductive decisions than might be surmised by looking at unplanned pregnancy rates. Consistent with the qualitative literature (e.g., Edin and Kefalas 2005), our findings suggest that many unplanned pregnancies are not entirely unintended or at least that women may try harder to avoid unwanted or mistimed pregnancies in some circumstances than in others. Indeed, our findings buttress the findings of Schneider and Hastings (2015) and Ananat, GassmanPines, and Gibson-Davis (2013), both of whom find that poor economic conditions are associated with reduced fertility for groups with high unintended pregnancy rates. Additionally, our findings suggest that policies or interventions aimed at reducing unplanned pregnancies have the potential to be effective, given that such pregnancies are responsive to economic conditions.

\section{Notes}

1 Nepomnaschy and colleagues (2006) find that elevated maternal cortisol levels (an indicator of stress) are linked with elevated risk of pregnancy loss in the first three weeks after conception.

2 Per NCHS regulations, all cell sizes have to be above a specified size. Because of this, we had to pool women ages 35-44 into a single category.

3 Unemployment rates are available monthly, but the estimation error is high for the monthly estimates. Foreclosure rates are available quarterly; we use the annual measures for consistency with the other economic measures.

4 State-level estimates were unavailable for eight states with small populations and small sample sizes in the Survey of Consumers.

5 NCHS restrictions bar us from presenting certain descriptive statistics, including the median and interquartile range, for NSFG survey participants. Instead, we present the range for all 50 states. 
6 CBSA unemployment rate (logged) is from the Local Area Unemployment Series. These rates are not available for women in rural areas.

7 We thoroughly investigated using state fixed effects. We were able to model pregnancy in models with state fixed effects using the full NSFG sample, but models with state fixed effects would not converge for our analytic sample, which has a much smaller sample size.

8 Restrictions imposed by NCHS limited our ability to examine small subgroups.

972.8 percent of unpartnered women were sexually active in the observation period.

1099 percent of married and cohabiting women were sexually active in the observation period.

1181.9 percent of married women, 82.9 percent of cohabiting women, and 90.0 percent of unpartnered (sexually active) women used contraceptives.

\section{References}

Ananat, Elizabeth Oltmans, Anna Gassman-Pines, and Christina Gibson-Davis. (2013). Community-wide job loss and teenage fertility: Evidence from North Carolina. Demography, 50(6), 2151-2171. https://doi.org/10.1007/s13524-013-0231-3

Barber, Jennifer S., William G. Axinn, and Arland Thornton. (1999). Unwanted childbearing, health, and mother-child relationships. Journal of Health and Social Behavior, 40(3), 231-257. https://doi.org/10.2307/2676350

Bongaarts, John. (1978). A framework for analyzing the proximate determinants of fertility. Population and Development Review, 4 (1), 105-132. https: //doi .org/10.2307/1972149

Budig, Michelle J., and Paula England. (2001). The wage penalty for motherhood. American Sociological Review, 66(2), 204-225. https://doi.org/10.2307/2657415

Carlson, Marcia J., and Frank F. Furstenberg. (2006). The prevalence and correlates of multipartnered fertility among urban U.S. parents. Journal of Marriage and Family, 68(3), 718-732. https://doi.org/10.1111/j.1741-3737.2006.00285.x

Cherlin, Andrew, Erin Cumberworth, S. Philip Morgan, and Christopher Wimer. (2013). The effects of the Great Recession on family structure and fertility. The ANNALS of the American Academy of Political and Social Science, 650 (1), 214-231. https : //doi.org/10. $1177 / 0002716213500643$

Davis, Kingsley, and Judith Blake. (1956). Social structure and fertility: An analytic framework. Economic Development and Cultural Change, 4(3), 211-235. https://doi.org/10. $1086 / 449714$

Edin, Kathryn, and Maria Kefalas. (2005). Promises I can keep: Why poor women put motherhood before marriage. Berkeley, CA: University of California Press.

Finer, Lawrence B., and Mia R. Zolna (2011). Unintended pregnancy in the United States: Incidence and disparities, 2006. Contraception, 84 (5), 478-485. https://doi .org/10. $1016 / j$. contraception 2011.07 .013

Finer, Lawrence B., and Mia R. Zolna. (2016). Declines in unintended pregnancy in the United States, 2008-2011. New England Journal of Medicine, 374(9), 843-852. https ://doi . org/10.1056/NEJMsa1506575

Guzzo, Karen Benjamin, and Hayford, Sarah R. (2012). Unintended fertility and the stability of coresidential relationships. Social Science Research, 41 (5), 1138-1151. https : //doi .org/ $10.1016 / j$.ssresearch.2012.03.002 
Guzzo, Karen Benjamin (2014). New partners, more kids: Multiple-partner fertility in the United States. The ANNALS of the American Academy of Political and Social Science, 654 (1), 66-86. https://doi.org/10.1177/0002716214525571

Hayford, Sarah R. (2013). Marriage (still) matters: The contribution of demographic change to trends in childlessness in the United States. Demography, 50 (5), 1641-1661. https : //doi.org/10.1007/s13524-013-0215-3

Hoynes, Hilary, Douglas L. Miller, and Jessamyn Schaller (2012). Who suffers during recessions? The Journal of Economic Perspectives, 26(3), 27-48. https://doi . org/10.1257/jep. 26.3 .27

Jones, Rachel K., and Kathryn Kost. (2007). Underreporting of induced and spontaneous abortion in the United States: an analysis of the 2002 National Survey of Family Growth. Studies in Family Planning, 38(3), 187-197. https://doi.org/10.1111/j.1728-4465.2007. $00130 . x$

Joyce, Theodore J., Robert Kaestner, and Sanders Korenman. (2000). The effect of pregnancy intention on child development. Demography, 37 (1), 83-94. https://doi .org/10. 2307/ 2648098

Lang, Kevin, and Ana Nuevo-Chiquero (2012). Trends in self-reported spontaneous abortions 1970-2000. Demography, 49(3), 989-1009. https://doi.org/10.1007/ s13524-012-0113-0

Mani, Anandi, Sendhil Mullainathan, Eldar Shafir, and Jiaying Zhao. (2013) Poverty impedes cognitive function. Science, 341(6149), 976-980. https://doi.org/10.1126/science. 1238041

Mazzaferro, Kathryn E., Pamela J. Murray, Roberta B. Ness, Debra C. Bass, Nadra Tyus, and Robert L. Cook. (2006). Depression, stress, and social support as predictors of high-risk sexual behaviors and STIs in young women. Journal of Adolescent Health, 39(4), 601-603. https://doi.org/10.1016/j.jadohealth.2006.02.004

Monte, Lindsay M., and Renee R. Ellis. (2014). Fertility of women in the United States: June 2012. Current Population Reports (pp. 20-575). U.S. Census Bureau, Washington, DC.

Morgan, S. Philip, Erin Cumberworth, and Christopher Wimer (2011). The Great Recession's influence on fertility, marriage, divorce, and cohabitation. In Grusky, David B., Bruce Western, and Christopher Wimer (Eds.), The Great Recession (pp. 220-246). New York: Russell Sage.

Mosher, William D., Jo Jones, and Joyce C. Abma. (2012). Intended and unintended births in the United States: 1982-2010. National Health Statistics Report, 55. Hyattsville, MD: National Center for Health Statistics.

Musick, Kelly. (2002). Planned and unplanned childbearing among unmarried women. Journal of Marriage and Family, 64(4), 915-929. https ://doi .org/10.1111/j .1741-3737. 2002.00915.x

Nepomnaschy, Pablo A., Kathleen B. Welch, Daniel S. McConnell, Bobbi S. Low, Beverly I. Strassmann, and Barry G. England. (2006). Cortisol levels and very early pregnancy loss in humans. Proceedings of the National Academy of Sciences of the United States of America, 103(10), 3938-3942. https://doi.org/10.1073/pnas.0511183103

Pazol, K., Creanga, A. A., Zane, S. B., Burley, K. D., and Jamieson, D. J. (2012). Abortion surveillance - United States, 2009. Morbidity and Mortality Weekly Report 61(8), 1-44. Atlanta, GA: Centers for Disease Control and Prevention.

Saleem, Haneefa T., and Pamela J. Surkan. (2014). Parental pregnancy wantedness and child social-emotional development. Maternal and Child Health Journal, 18(4), 930-938. https://doi .org/10.1007/s10995-013-1320-z 
Schneider, Daniel. (2015). The Great Recession, fertility, and uncertainty: evidence from the United States. Journal of Marriage and Family, 77 (5), 1144-1156. https ://doi .org/10. $1111 /$ jomf. 12212

Schneider, Daniel, and Orestes P. Hastings. (2015). Socioeconomic variation in the effect of economic conditions on marriage and nonmarital fertility in the United States: Evidence from the Great Recession. Demography, 52(6), 1893-1915. https://doi.org/10.1007/ s13524-015-0437-7

Sobotka, Tomáš, Vegard Skirbekk, and Dimiter Philipov. (2011). Economic recession and fertility in the developed world. Population and Development Review, 37(2), 267-306. https : //doi.org/10.1111/j.1728-4457.2011.00411.x

$\mathrm{Su}$, Jessica Houston. (2012). Pregnancy intentions and parents' psychological well-being. Journal of Marriage and Family, 74 (5), 1182-96. https ://doi .org/10.1111/j.1741-3737. 2012.01006.x https://doi.org/10.1111/j.1741-3737.2012.01006.x

Sutton, Paul D., Brady E. Hamilton, and T. J. Mathews. (2011). Recent decline in births in the United States, 2007-2009." NCHS Data Brief, 60. Hyattsville, MD: National Center for Health Statistics.

Sweeney, Megan M. (2010). The reproductive context of cohabitation in the United States: Recent change and variation in contraceptive use. Journal of Marriage and Family, 72 (5), 1155-1170. https://doi.org/10.1111/j.1741-3737.2010.00756.x

Sweeney, Megan M., and Raley, R. Kelly. (2014). Race, ethnicity, and the changing context of childbearing in the United States. Annual Review of Sociology, 40, 539-558. https: //doi.org/10.1146/annurev-soc-071913-043342

Trussell, James. (2011). Contraceptive failure in the United States. Contraception, 83 (5), 397-404. https://doi.org/10.1016/j.contraception.2011.01.021

U.S. Department of Health and Human Services. (2011). Public use data file documentation: 2006-2010 National Survey of Family Growth" Hyattsville, MD: National Center for Health Statistics. http://www.cdc.gov/nchs/data/nsfg/nsfg_2006-2010_userguide_ maintext.pdf

Wolff, Edward N., Lindsay A. Owens, Esra Burak. (2011). How much wealth was destroyed in the Great Recession? In Grusky, David B., Bruce Western, and Christopher Wimer (Eds.), The Great Recession (pp. 127-158). New York: Russell Sage.

Acknowledgements: The authors gratefully acknowledge the support of the University of Wisconsin Institute for Research on Poverty Emerging Scholars Family Complexity Small Grant program.

Christine Percheski: Department of Sociology and Institute for Policy Research, Northwestern University. E-mail: c-percheski@northwestern.edu.

Rachel Tolbert Kimbro: Department of Sociology, Rice University. E-mail: rtkimbro@rice.edu. 